\title{
Chemical arms: a sea of troubles
}

RECENTLY, the worldwide press has reported on how rumours of Soviet chemical warfare in Afghanistan have led to increased support in the US for the resumption of manufacture of chemical weapons. Europe should take note of these reports, for if US chemical weapons production does resume it will almost certainly have been endorsed beforehand by at least one European government. Prior experience suggests that such endorsement will not receive prior parliamentary debate.

For several years European members of NATO have been under pressure from the United States to reconsider their positions on chemical weapons. Existing NATO policy is that chemical weapons are to be used only for retaliation in kind within the prevailing 'flexible response' defence strategy. US officials believe that this policy requires NATO to integrate a retaliatory chemical capability much more closely into its military planning and posture than it has so far done. France and the US are alone within the alliance in possessing significant stocks of poison gas, and, although certain other member-states, such as Britain, keep themselves informed about how to use chemical weapons, the remainder do not. West Germany, in particular, has long committed itself against acquiring its own, and has declared that it will not seek access to anyone else's.

The prevalent European view has been that the threat of escalation (including nuclear weapons release) implicit in the flexible response strategy, coupled with the antichemical protection of NATO forces, provides sufficient safeguard against Soviet resort to chemical warfare. Antichemical protection is currently being upgraded, and is capable of negating the massdestructiveness of chemical weapons on the battlefield, albeit at some cost to fighting efficiency. French and American chemical weapons are seen as a useful extra precaution to the extent that they can act as an additional deterrent - a belief which may or may not be sound.

Suggestions that the NATO chemical retaliatory capability should be expanded have been opposed on several grounds. First, such an expansion could be interpreted as a sign of diminished resolve to use nuclear weapons. Increased deterrence of chemical warfare would then have been bought at cost of reduced overall deterrence. Secondly, there would be greater returns for European security from investment in improved conventional capabilities. In addition, a new chemical armament drive would compromise the current negotiations on chemical disarmament, which in theory offer the best safeguard against chemical attack.

While many Americans appreciate such arguments, some maintain that the present state of nuclear parity now thought to exist between the US and the USSR, together with the apparent Soviet interest in chemical weapons, strengthens the requirement for a special chemical-warfare deterrent. For reasons that are not entirely clear, they believe that their existing special deterrent - in the form of the one to two weeks' supply of US chemical munitions now on hand in West Germany, replenishable from much greater American stockpiles - is insufficient. Hence the plans for a new chemical weapons factory with a projected expenditure, so it is said in the American press, of $\$ 1,300$ millions, on an output of nerve gas artillery shells, bombs and warheads.

Such a programme can make sense only if Europeans undertake, at the very least, to accept the new weapons on their soil. This is the endorsement which potential host countries will be asked, once again, to give.

There are few public signs of the way European opinion may go on poison gas. The Afghan allegations, however unsubstantiated, could be influential, succeeding as they do a whole series of others that the USSR will use chemical and even biological warfare whenever it is militarily expedient, regardless of treaty constraints. Reports have alleged Soviet backing for Vietnamese chemical warfare in Laos and Kampuchea, expansion of Soviet chemical-weapons stocks, and Soviet violation of the 1972 Biological Weapons Disarmament Convention. Yet, as a recently published review of these different charges shows in some detail*, no solid evidence has been disclosed for any of them.

Should the allegations be true, the implications for the West would be serious. The problem is that uncertainty about them extends to government - a symptom of the generally poor state of western chemical warfare intelligence. Because there is little hard information, these reports are in fact rooted in worst-case assumptions. Capabilities are estimated by equating them with the requirements for chemical weapons set by Soviet military doctrine on chemical warfare which, though not known with any precision, is assumed to teach maximum exploitation of all battlefield target effects available from toxic chemicals. The stockpile tonnage estimates quoted recently in the US press (Nature 13 March, 1980) are no exception. Their belittling of American capabilities is also commonplace, compounded in this instance by a confusion of chemical weapons with poison gas: it is the latter, not the former, of which the Americans have 42,000 tons - a supply sufficient to fill up to half a million tons of chemical munitions.

Absurdly, such estimates of Soviet stocks are frequently quoted by military analysts and journalists as evidence of the intentions from which, in fact, they were deduced. Because the Soviets have an enormous supply of chemical weapons, such comment goes, they must be planning for protracted chemical warfare of their own initiation. Yet such hard quantitative information as there is, drawn mostly from sightings of Soviet depots in forward areas believed to contain chemical weapons, is equally consistent with a retaliation-only posture, similar to NATO's.

In the historical record of US and Soviet chemical warfare preparedness since World War II, there is clear evidence that the programmes of one side have driven, at least in part, those of the other. The US stopped adding to its stocks of chemical weapons in 1969; the USSR, a year or two later. It would be highly dangerous if a cycle in the opposite direction were now to be set in motion again. The chemical arms limitation talks in Geneva, which are proceeding in both a US-Soviet working group and within the 40-nation UN Committee on Disarmament, provide what is probably the only available channel of communication for resolving such uncertainties. The first priority for the West in its policy-making on chemical warfare must therefore be to keep this channel open.

Over the years the negotiations have advanced to the point where they are now turning on intricate questions of the controls that must be placed on national chemical industries, and on particular military facilities, in the interests of adequate treaty verification. These raise issues of such delicacy that negotiation can proceed only if there is mutual confidence.

If the Soviets are innocent of the chemical and biological warfare allegations against them, a new western chemical armament drive cannot fail to deepen mistrust and suspicion. Although a go-ahead for the US binary nerve-gas plans could strengthen the position from which the West is negotiating, it could at the same time destroy the basis of negotiation. While Europeans may not be able to do very much to promote chemical arms control, they may soon be in a position to kill it.

* Chemical and Biological Warfare: Analysis of Recent Reports concerning the Soviet Union and Vietnam, March 1980, pp42. A vailable as ADIU Occasional Paper no 1 , from the Armament \& Disarmament Information Unit, University of Sussex, Brighton BNI $9 R F$, UK price fl.50 plus postage. 